EPJ Web of Conferences 31, 00029 (2012)

DOI: $10.1051 /$ epjconf/20123100029

(C) Owned by the authors, published by EDP Sciences - SIF, 2012

\title{
Studies of the equation of state of asymmetric nuclear matter with R3B at FAIR
}

R. LEMMON

Daresbury Laboratory, Cheshire, UK

\begin{abstract}
The R3B experiment at FAIR will offer unique opportunities worldwide to study the properties of bulk asymmetric nuclear matter, e.g. the phase diagram, equation of state, symmetry energy, transport coefficients and in-medium cross sections. The experiment will take advantage of the intense radioactive beams produced by the SuperFRS with energies up to $2 \mathrm{AGeV}$. We will outline this physics programme and describe the detector sub-systems of R3B which will enable these measurements. Some detectors are already under construction while others are at the planning/R\&D stage.
\end{abstract}

This is an Open Access article distributed under the terms of the Creative Commons Attribution License 2.0, which permits unrestricted use, distribution, and reproduction in any medium, provided the original work is properly cited. 